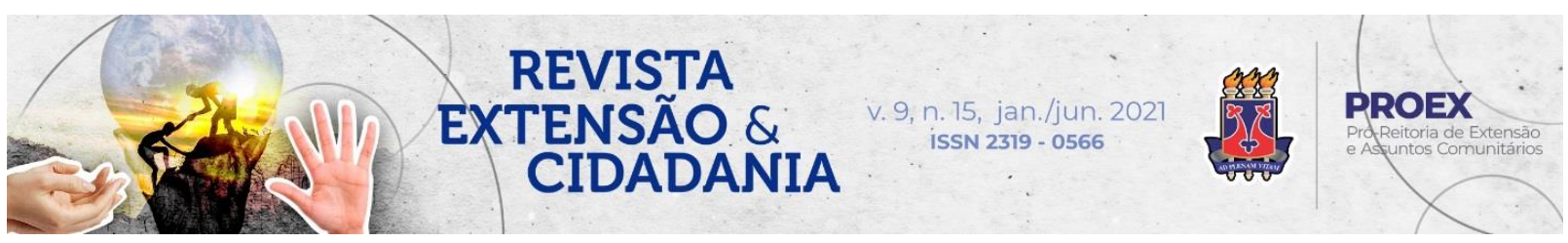

DOI: $10.22481 /$ recuesb.v9i15.8634

\title{
OFICINA SOBRE VIOLÊNCIA CONTRA A MULHER NO ÂMBITO DO PROJETO MULHERES IFSP: UM RELATO DE ESCUTA
}

\section{Workshop on violence against women within the scope of the women IFSP project: a listening approach}

Ana Carolina Vila Ramos dos Santos ${ }^{1}$

Resumo: Este trabalho apresenta um relato de experiência de realização de uma oficina sobre violência contra a mulher oferecida no projeto "Empoderamento Feminino através da geração de renda pelas vendas" desenvolvido no âmbito do Projeto Mulheres IFSP no campus São Paulo-Pirituba. A metodologia aplicada é a de oficina em dinâmica de grupo que adota como princípio a escuta qualificada e compartilhamento das experiências das discentes e assume como objetivo fomentar um espaço de acolhimento por meio do qual as participantes possam elaborar simbolicamente o tema e desenhar possibilidades de saída de situações de abuso por meio do apelo a mediadores institucionais e pela percepção de si mesma como pessoa cuja vida e dignidade precisam ser garantidas.

Palavras-chave: Violência contra a mulher. Empoderamento feminino. Direitos humanos.

Abstract: This paper presents an experience report on conducting a Workshop on Violence against Women offered in the project "Female Empowerment through the generation of income from sales" developed within the scope of the Women IFSP Project in the São Paulo-Pirituba campus. The methodology applied is the workshop in group dynamics that adopts the principle of qualified listening and sharing of the students' experiences and aims to foster a welcoming space through which the participants can symbolically elaborate the theme and design possibilities for the exit of abuse situations through the appeal to institutional mediators and through the perception of herself as a person whose life and dignity need to be guaranteed. keywords: violence against women; female empowerment; human rights.

\footnotetext{
${ }^{1}$ Doutora em Sociologia. Professora EBTT de Sociologia no Instituto Federal de Educação, Ciência e Tecnologia de São Paulo (IFSP), campus São Paulo-Pirituba. Orcid: https://orcid.org/0000-0001-7270-2448 Email: carolina.vila@ifsp.edu.br
} 


\section{Introdução}

Este trabalho apresenta um relato de experiência de uma oficina sobre violência contra mulher realizada no âmbito do projeto "Empoderamento Feminino através da geração de renda pelas vendas" proposto por uma equipe multidisciplinar do campus São Paulo-Pirituba ${ }^{2}$, contemplado por financiamento no bojo do Projeto IFSP Mulheres. A proposta do projeto era atender um grupo de 25 mulheres (maiores de 16 anos), residentes nos distritos de Pirituba e Jaraguá (localizados na região Noroeste da cidade de São Paulo), com pouca ou nenhuma escolaridade e em condições de vulnerabilidade social para capacitação profissional, por meio do curso de formação inicial e continuada (FIC) de promotora de vendas e outras ações de extensão como palestras, oficinas e minicursos que tinham como objetivo a inclusão cidadã das discentes. O recebimento de uma bolsa mensal garantia a presença diária das estudantes no campus pelo decurso do projeto. O projeto tomava como suporte teórico os entrelaçamentos entre caminhos para superação da vulnerabilidade social e empoderamento feminino entendido em seus múltiplos sentidos articulados (financeiro, educacional e subjetivo).

O projeto foi desenvolvido a partir de uma parceria firmada com instituições da sociedade civil atuantes no território do noroeste paulistano: a ONG PAC- Projeto Amigos das Crianças e o SEBRAE. A ONG PAC - Projetos Amigos das Crianças tem, no território do Noroeste paulistano, uma longa história de atuação na promoção de ações e serviços socioassistenciais; a longa experiência da ONG foi crucial na divulgação, seleção e encaminhamento de mulheres nas condições especificadas no projeto. Houve também a participação do SEBRAE em palestras sobre empreendedorismo para fortalecer os conhecimentos abordados nas disciplinas do curso.

O projeto foi desenvolvido no segundo semestre de 2019 (agosto a dezembro) e foi constituído como um curso FIC (curso de formação inicial e continuada) cujos objetivos eram 1) oferecer qualificação profissional às alunas para atuarem como promotoras de vendas (atuação em estabelecimentos do comércio varejista ou atacadista auxiliando os clientes na

\footnotetext{
${ }^{2}$ O projeto foi coordenado pela Profa. Ma. Claudia Almerindo de Souza Oliveira e contou com a participação da pedagoga Rylla Zanini Silva; nutricionista Bianca Blanco; assistente de alunos Kamili Oliveira Santana e professores Prof. Dr. Danilo Marcondes de Alcantara; Profa. Dra. Elisangela Lizardo de Oliveira; Prof. Dr. Felipe Rodrigues Martinez Basile; Prof. Me. Fernando Cesar Mendonca; Profa. Dra. Hania Cecilia Pilan; Prof. Me. Ivan Miletovic Mozol, Prof. Dr. Junot de Oliveira Maia, Profa. Ma.. Maysa Ciarlariello Cunha Rodrigues, Prof. Me. Nilton Pereira dos Santos; Prof. Me. Oertes Alves Souza; Prof. Dr. Robson Barbosa; Profa. Dra. Teresa Helena Buscato Martins e Prof. Dr. Thiago Pedro Donadon Homem.
}

Revista Extensão \& Cidadania, v. 9, n. 15, p. 154-165 jan./jun. 2021. 
escolha de produtos e serviços) e 2) despertar nas discentes a percepção de que elas são sujeitos de sua própria história e possíveis multiplicadoras das experiências vivenciadas no curso.

A carga horária do curso era de 160 horas distribuídas em 10 disciplinas alocadas em Núcleo Comum (Linguagens, códigos e suas tecnologias; Matemática básica; Mulheres no Brasil: Cidadania, Direitos e Luta por Igualdade; Saúde da mulher; Educação socioambiental e sustentabilidade e Inclusão digital) e Núcleo Tecnológico (Técnicas de Vendas; Comunicação digital para vendas; Economia para vendas e Inglês para vendas).

A oficina sobre violência contra mulher foi oferecida como parte do conteúdo complementar do curso e teve carga horária de 4 horas distribuídas em uma única tarde. A carga horária diminuta e a metodologia da oficina em dinâmica de grupos tornam tal atividade replicável em outros cursos (de curta ou longa duração) e, por esta razão, entendo que a publicização da atividade pode tornar possível sua reprodução em múltiplas ocasiões de modo a oportunizar espaços para abordagem da violência contra mulher, uma questão social que nos interroga diariamente acerca dos limites de nossa democracia.

A violência contra a mulher é uma questão estrutural no Brasil e demanda ações nos mais variados níveis de governo e engajamento da sociedade civil com a perspectiva de garantia de direitos mínimos e dignidade às mulheres. Esta oficina se propõe a contribuir neste esforço ao promover uma discussão sobre violência contra mulher que privilegie uma escuta qualificada e o compartilhamento de experiências no interior de um grupo, no qual o sentimento de solidão seja diminuído em favor da percepção de que se trata de um problema social compartilhado por muitas mulheres; a identificação e delineamento da questão é um passo inicial para o desenho de possibilidades de saídas da situação de abuso que podem ser encontradas no apelo a mediadores institucionais (escola, polícia, prefeitura) e pela percepção de si mesma como pessoa cuja vida e dignidade precisa ser garantida.

Nas próximas seções, apresento uma síntese do debate sobre violência contra mulher na literatura sociológica para, em seguida, apresentar a metodologia e discussão dos resultados da oficina oferecida ao grupo de mulheres.

\section{Violência contra mulher: o debate na literatura para o desenho da metodologia.}

A violência contra a mulher é um fenômeno que coloca à prova, diuturnamente, a democracia brasileira; a vida e a dignidade de mulheres brasileiras são colocadas em risco pela perenidade dos valores patriarcais em uma sociedade que se imagina civilizada. Segundo Mapa

Revista Extensão \& Cidadania, v. 9, n. 15, p. 154-165 jan./jun. 2021. 
da Violência 2015. Homicídio de mulheres no Brasil (WAISELFISZ, 2015), o Brasil destacase, no panorama internacional, como país de alta letalidade para as mulheres (4,8/100 mil mulheres): o país ocupa o quinto lugar atrás de El Salvador (8,9/100 mil mulheres), Colômbia (6,3/100 mil mulheres), Guatemala (6,2/100 mil mulheres) e Rússia (5,3/100 mil mulheres). Em 2018, a taxa de homicídio de mulheres era de 4,3/100 mil mulheres com um destaque que ilumina a desigualdade racial: em 2018, 68\% das mulheres assassinadas eram negras (IPEA, 2020).

A violência contra a mulher não é um fato novo: as séries históricas de estatísticas criminais demonstram que se trata de uma questão estrutural (WAISELFISZ, 2015; IPEA, 2020). O que é novo, e muito recente, é a preocupação com a superação dessa violência como condição necessária para a construção de uma sociedade civilizada, moderna e democrática. A construção da violência contra a mulher como uma questão social que merece atenção e que indica os limites da democracia moderna se deu graças à atuação do movimento feminista que logrou em construir, ao longo de décadas de atuação, um debate público de condenação deste tipo de violência; o resultado desta luta política que confere humanidade às mulheres é a formulação e implementação de políticas públicas de enfrentamento da violência praticada contra as mulheres. No Brasil, desde a década de 1980, se desenham os primeiros esboços de atendimento às vítimas de violência com a criação das delegacias de atendimento especializadas neste tipo de violência e toda uma rede- ainda incipiente em 2021 - de atendimento de saúde e psicossocial à mulher vítima de violência.

A Lei Maria da Penha (Lei n 11.340/2006), a Lei do "Minuto Seguinte" (Lei n 12.845/2013) e a Lei do Feminicídio (Lei no 13.104/2015) indicam as conquistas da longa luta feminista não apenas pela criminalização da violência contra as mulheres, mas também, e fundamentalmente, pela consolidação de estruturas estatais específicas (o aparelho policial e/ou jurídico, rede de atendimento de saúde e psicossocial) que podem ser mobilizadas para proteger as vítimas e/ou punir os agressores.

Importante recuperar, sinteticamente, tal percurso histórico. Na teoria sociológica clássica, a análise da violência está associada ao papel de controle social realizado pelo Estado Moderno. Sob esta perspectiva, o Estado é tomado como órgão central de controle pois detém o monopólio legítimo da violência para controle de desordens sociais, ameaças à propriedade e garantias de direitos individuais mínimos. Articulados à teoria do Estado, os estudos sobre a violência tenderam a equacionar a violência contra a mulher sob o amplo manto da violência interpessoal sem atentar para a especificidade de gênero (BANDEIRA,2014).

Revista Extensão \& Cidadania, v. 9, n. 15, p. 154-165 jan./jun. 2021. 
Outra leitura difundida no período sobre a violência contra a mulher é aquela que a atribui exclusivamente à pobreza, isto é, resolvida a questão do acesso a bens e recursos, a violência contra a mulher também seria solucionada tal como se a violência contra a mulher fosse fenômeno restrito a algumas experiências de classe que se afastam do ideal civilizatório burguês. Desde o início dos anos 1970, as feministas têm denunciado a violência contra a mulher apontando os limites dessas duas leituras muito difundidas sobre a violência contra a mulher, porém somente na década de 1980 é que esse fenômeno veio a ser apresentado como questão pública, categoria sociológica e área de pesquisa.

No Brasil, para um exemplo próximo, além de se conformar como importante área de pesquisa, o tema passa ser a principal bandeira do movimento feminista. O movimento feminista brasileiro teve êxito em demonstrar, por meio da denúncia de casos bárbaros de violência contra mulheres de classe média, que embora a desigualdade social exponha a mulher pobre e negra a episódios de violência, é a desigualdade entre os gêneros, que tem como essência a posição inferiorizada da mulher em nossa sociedade, que explica tais casos. Lembrem-nos que, até o final dos anos 1970, os registros jornalísticos e as práticas jurídicas desses assassinatos assentavam-se no argumento da legítima defesa da honra do homem e não na defesa da vida e dignidade da mulher. O caso do assassinato de Ângela Diniz por Doca Street, em 1976, é paradigmático: primeiramente, o réu foi absolvido com a justificativa de que havia sido um crime provocado pelo comportamento da vítima. Em um segundo julgamento, o movimento feminista logrou em mobilizar a opinião pública e o desfecho foi a condenação do assassino.

O caso do assassinato de Ângela Diniz demonstra que a violência contra a mulher não se refere a uma pessoa considerada igual ou que é vista nas mesmas condições de existência e valor que o seu perpetrador: a violência contra a mulher ocorre motivada pelas expressões de desigualdades baseadas na condição de gênero (BANDEIRA, 2014). Dois conceitos formulados no diálogo intenso entre movimento social e academia foram contributos importantes no desvelamento desta desigualdade e no equacionamento da questão, "gênero" e "patriarcado".

Por meio do conceito de gênero aplicado à análise das relações entre homens/masculino e mulheres/feminino, o movimento feminista, em meados da década de 1980, desconstruiu a ideia corrente de que o aparato sexual era inerente à natureza das mulheres e dos homens, colocando as concepções acerca dos sexos fora do âmbito biológico (sexo) e as inscrevendo na história e nas relações sociais (gênero). As feministas tiveram sucesso ao demonstrar que a

Revista Extensão \& Cidadania, v. 9, n. 15, p. 154-165 jan./jun. 2021. 
violência contra a mulher está ligada aos significados atribuídos, de modo cristalizado, à masculinidade (símbolo do poder e da dominação), à feminilidade (epítome da fragilidade e submissão) e à relação entre homens e mulheres marcada, em nossa cultura, pela reprodução secular de valores patriarcais que colocam a mulher e o feminino em uma relação subordinada ao homem e ao masculino (SCOTT, 1995).

Nas décadas de 1980 e 1990, o conceito de patriarcado passa a ser largamente mobilizado pelo movimento feminista como um dos fatores explicativos da persistência da violência contra a mulher. Patriarcado, tomado como a reprodução de valores e práticas que tomam as mulheres como o Outro submetido ao desejo dos homens, traz significados e desdobramentos importantes para que se possa compreender a manutenção do ordenamento familiar burguês que tem a submissão do feminino ao masculino como princípio. No Brasil, por exemplo, o ditado "em briga de marido e mulher não se mete a colher" é questionado pelo movimento feminista por meio da politização de relações sociais outrora tomadas como naturais e inquestionáveis: o pessoal torna-se político e valores e práticas cristalizadas nas relações entre homens/masculino e mulheres/feminino, na esfera pública e privada, passam a ser tematizadas e subvertidas em favor da vida e dignidade das mulheres (BANDEIRA, 2014).

Apesar das conquistas e da luta cotidiana de movimentos sociais, persiste, em nossa sociedade, uma certa tolerância à violência contra a mulher tomada como "tempero do amor" ou mesmo como corretivo para comportamentos de mulheres que escapam à norma da feminilidade em uma sociedade de valores patriarcais. Sob este ponto de vista, a tolerância à violência contra mulheres, denotada pela sua perenidade enquanto questão social, não se caracteriza como patologia ou como desvio individual, mas sim como uma espécie de permissão social concedida e acordada com os homens como forma de correção de comportamentos que infringem normatividades de gênero e sexualidade (BANDEIRA, 2014; GREGORI, 1989).

O ciclo da violência contra mulher, tão bem caracterizado pela literatura (GREGORI, 1989), demonstra como a tolerância a agressões verbais, ciúme possessivo, práticas de controle da vida íntima e financeira da mulher pelo homem são considerados prosaicos e, até mesmo, testemunhas do amor romântico. A tolerância a tais práticas e discursos associada a sentimentos contraditórios como a esperança de o agressor mudar de comportamento, o medo de represálias e de novas agressões mais graves, o medo de perder a guarda dos filhos, a censura da família e da comunidade, a dependência afetiva e econômica e tantas outras questões, forjadas na experiência subjetiva de cada mulher, tornam o rompimento de uma relação violenta um tour de force (GREGORI, 1989).

Revista Extensão \& Cidadania, v. 9, n. 15, p. 154-165 jan./jun. 2021. 
Na próxima seção, será apresentada a metodologia da oficina que tem como objetivo enfrentar tais questões por meio da escuta qualificada e do acolhimento de um grupo de mulheres que compartilham as mesmas dores e podem vislumbrar juntas possibilidades de saída. Os resultados da aplicação da metodologia são apresentados para avaliação da efetividade da metodologia escolhida.

\section{A oficina: metodologia e resultados}

A Oficina foi conduzida por uma única moderadora ao longo de uma tarde (4 horasaula) com uma turma de 23 mulheres maiores de idade, residentes no entorno do campus do IFSP São Paulo-Pirituba e participantes do projeto "Empoderamento Feminino através da geração de renda pelas vendas". A oficina toma os mesmos supostos teóricos adotados pelo projeto, a saber: a articulação entre possibilidades para superação da vulnerabilidade social e empoderamento feminino entendido em seus múltiplos sentidos articulados (empoderamento financeiro, educacional e subjetivo). A oficina tomou como objetivos: 1) apresentar a temática violência contra mulher a partir de uma metodologia baseada na escuta e no diálogo; 2) oferecer subsídios para o enfrentamento da violência no cotidiano das discentes; 3) promover uma perspectiva de cuidado de si e do Outro com base nos princípios da dignidade humana.

A metodologia aplicada é a oficina de dinâmica de grupo; tal metodologia afasta o caráter puramente informativo que discentes esperam no ambiente escolar e adota uma perspectiva que seja capaz de compreender as participantes em suas diversas e contraditórias dimensões; Gregori (1989) chama a atenção para o caráter opaco e contraditório que a violência assume na experiência de mulheres que ela escutou em um serviço de atendimento a mulheres em situação de violência e demonstra que, para além do acesso a informações, aquelas mulheres buscavam espaços para serem ouvidas em suas queixas, suas dores e seus amores.

A proposta da oficina, portanto, não se reduz à "transmissão de informações de um sujeito que sabe para outro que aprende" (CARVALHO; RODRIGUES; MEDRADO, 2005: p.377), mas propõe-se a estabelecer diálogos e vínculos entre mulheres com experiências similares que possam juntas refletir sobre o tema. Foi feito um esforço para que a oficina se construísse como um espaço para reflexão e elaboração de sentimentos associados a experiências de violência de modo que reconsiderações de posturas pudessem ser delineadas pelas próprias participantes.

Revista Extensão \& Cidadania, v. 9, n. 15, p. 154-165 jan./jun. 2021. 
A Oficina em dinâmica de grupo, tal como desenhada por Maria Lucia Afonso (2000), coaduna-se em uma metodologia estruturada a partir de uma questão que um determinado grupo se propõe a elaborar. Tal elaboração não se resume ao exercício da razão na análise da questão, mas toma como objetivo envolver as participantes de maneira integral, articulando práticas, pensamentos e sentimentos. A oficina integra informação, elaboração de afetos e vivências que a questão escolhida suscita e, com o intuito de produzir vínculos entre as participantes, são mobilizadas práticas de sensibilização, comunicação e reflexão com o intuito de produzir vínculos entre as participantes. À moderação do grupo cabe o papel de facilitadora da dinâmica do grupo, com uma atuação pontual que preze pelo fomento de um espaço dialógico e de acolhimento.

Tomando como inspiração o trabalho de Gregori (1989), a oficina desloca o olhar das mulheres tomadas sob a rubrica generalizante de oprimidas e tem como suposto a compreensão do fenômeno da violência na experiência subjetiva de cada participante. O desenho da oficina não supõe que as mulheres permaneçam em relações abusivas pela falta de informação e que, portanto, o acesso à informação seria a panaceia para uma tomada de decisão crucial na vida destas mulheres. A oficina supõe que as experiências de violência vivenciadas por estas mulheres estão alicerçadas em valores e práticas de difícil compreensão, questionamento e subversão em uma sociedade de valores tão fortemente patriarcais como a brasileira. Como demonstra Gregori (1989), a violência contra a mulher precisa ser compreendida como parte do modelo moderno de casamento que explica a violência praticada pelo homem como parte da dinâmica do casal e dos papéis esperados dos homens e das mulheres em uma relação heteronormativa e monogâmica.

Assim, para além de oferecer informações sobre violência que muitas delas podem ter sofrido e ainda sofrem, a proposta principal da oficina é despertar nas mulheres sensibilidade para a questão desnaturalizando comportamento considerados toleráveis (agressões verbais, ciúme possessivo, práticas de controle da vida íntima e financeira e tantas outras ações); tal sensibilidade pode ser construída no diálogo com outras mulheres que as vivenciam e criam saídas para dilemas parecidos. O papel da mediadora, neste processo, é fundamental: longe de indicar ou suscitar no grupo prescrições do que fazer, a mediação deve privilegiar o processo de escuta e acolhimento para que cada mulher elabore, de forma simbólica e prática, saídas para a situação de violência. A oficina toma como suposto, portanto, que cada indivíduo tem seu tempo de elaboração e o espaço de diálogo precisa ser construído a partir desta premissa.

Revista Extensão \& Cidadania, v. 9, n. 15, p. 154-165 jan./jun. 2021. 
Assumindo tais supostos, apresento o relato da metodologia aplicada na oficina. No desenvolvimento da oficina, foram mobilizados os seguintes conteúdos atinentes aos objetivos estabelecidos: a violência contra a mulher no Brasil: uma breve história e panorama; o ciclo da violência contra a mulher; cuidado de si como chave do enfrentamento de relações abusivas; informações básicas sobre leis e instituições que oferecem atendimento gratuito a mulheres que são vítimas de violência. Considerando tais conteúdos, foi adotada a seguinte sequência na oficina: 1) Dinâmica das "máscaras"; 2) Apresentação e debate sobre o curta-metragem “Acorda Raimundo Acorda!” (1990); 3) Apresentação do "ciclo da violência" e o cuidado de si; 4) Leis de proteção às mulheres vítimas de violência: Lei Maria da Penha, Lei do minuto seguinte, Lei do feminicídio; 6) Distribuição de pequenos panfletos sobre a rede de atendimento na cidade de São Paulo.

O primeiro momento foi a apresentação de cada uma das participantes por meio da “dinâmica das máscaras"; foi distribuída para cada uma das participantes o desenho de uma máscara impresso em uma folha de sulfite e solicitou-se que cada uma anotasse na frente da máscara como as pessoas as veem (o que elas mostram para o mundo?) e no verso da máscara como elas próprias se veem (o que elas escondem? o que não contam para ninguém? como elas realmente são?). A condução da apresentação deve garantir a abertura das participantes para a discussão de um tema que é objeto de vergonha e de profundo sofrimento, a violência sofrida cotidianamente pelas mãos daqueles que elas amam e confiam. Para a turma para a qual a oficina foi oferecida, foi um momento crucial de abertura emocional para que todas conhecessem melhor umas às outras; neste momento, a mediação ficou restrita a garantir o momento de fala de cada uma e o grupo se constituiu claramente como um coletivo atento e acolhedor para cada uma das participantes.

O segundo momento da oficina foi a apresentação de um curta-metragem intitulado “Acorda Raimundo Acorda!” (1990); dirigido por Alfredo Alves e estrelado por Eliane Giardini, Zezé Mota, Paulo Betti e José Mayer, o filme propõe a inversão de papéis tradicionalmente atribuídos a homens e mulheres em nossa sociedade para demonstrar o cotidiano de mulheres marcado pelo machismo e violência. A apresentação do curta-metragem teve como objetivo debater com as estudantes como as diferenças de gênero são construídas histórica e socialmente e como estas produzem e reproduzem desigualdades e violências.

No grupo, a apresentação do filme suscitou risadas e a percepção de como "a vida da gente poderia ser diferente", mas também ficou claro como estereótipos sociais associados ao feminino e ao masculino estão presentes e resistem nas histórias de amores e violências

Revista Extensão \& Cidadania, v. 9, n. 15, p. 154-165 jan./jun. 2021. 
relatadas pelas mulheres; em consonância com o que foi relato por Gregori (1989), foi possível notar que, embora o discurso sobre a igualdade entre homens e mulheres despontasse nas falas das participantes, persistiam valores e discursos sobre as relações entre homens/masculino e mulheres/feminino marcadamente tradicionais-patriarcais.

O terceiro momento da oficina inicia-se pela apresentação, em uma projeção de slides de powerpoint, do "ciclo da violência contra a mulher" (Figura 1) enfatizando a dinâmica das relações violentas intercaladas pela "lua de mel" e pelo aumento da tensão que antecede episódios de agressões que se tornam cada vez mais violentos e graves. O panfleto está disponível na página no grupo do Facebook.

\section{Figura 1 - "Ciclo da violência" elaborado pelo coletivo feminista "Não me Kahlo"}

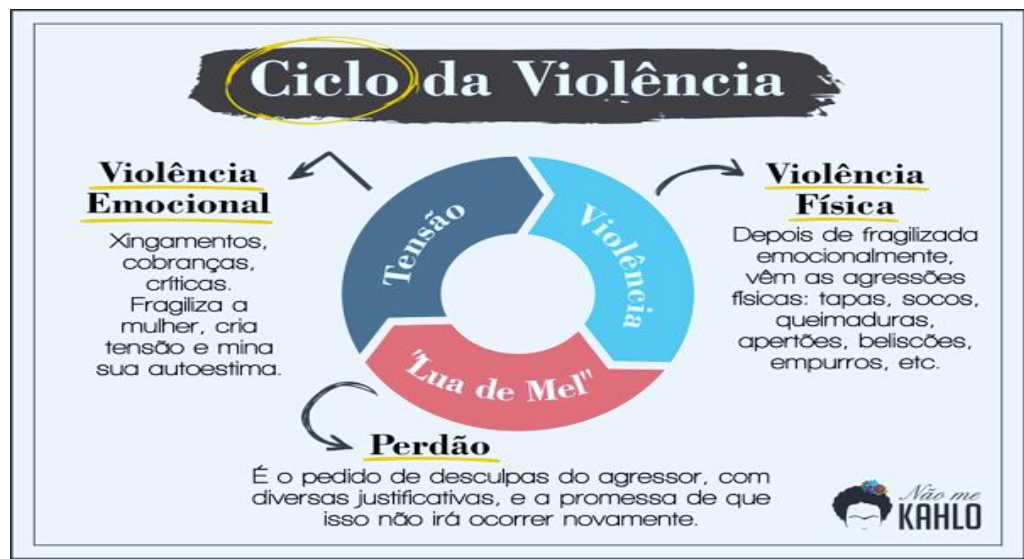

Fonte: Elaboração dos autores.

Como sair, então, de uma relação tão intricada em que amor e raiva estão tão virtualmente próximos? A mediadora apresentou, então, uma reflexão que retomou a necessidade de compreensão de que sofrer violência (em suas mais variadas formas desde de xingamentos, beliscões, controle da vida financeira até agressões como tapas e socos) não pode ser algo normalizado como parte de uma relação afetiva e íntima; a mediadora recuperou, então, histórias contadas no primeiro momento da oficina ("dinâmica das máscaras") e demonstrou que um primeiro movimento no enfrentamento do problema é reconhecê-lo. A reflexão passar a ser, então, como é difícil vislumbrar o rompimento com a situação de violência, pois a mulher dificilmente percebe que está envolta em situação desta natureza por esta ser normalizada no que as estudantes consideram, como reconheceram na oficina, como prova de amor (cenas de ciúme e controle do uso do celular e de redes sociais surgiram como exemplos).

Revista Extensão \& Cidadania, v. 9, n. 15, p. 154-165 jan./jun. 2021. 
Outro ponto levantado pela mediadora, com o auxílio de relatos e reflexões das participantes, é que, muitas vezes, mesmo quando a mulher percebe a situação, acredita que seu companheiro vai mudar se ela der uma chance, recaindo no "ciclo da violência" em uma infindável espiral de agressões e humilhações intercalada por juras de amor eterno. Reconhecer a situação de violência é um primeiro movimento, mas é preciso considerar que muitas mulheres podem ter diferentes tipos de dependências (um exemplo recorrente é a financeira, mas é preciso dar o peso devido à dependência afetiva associada ao ideal de complementação entre masculino e feminino na moderna sociedade ocidental). A saída, a ser construída pela experiência do grupo, é sempre cuidar de si reconhecendo que nenhuma mulher merece viver em uma relação violenta e que práticas consideradas inofensivas (ciúme possessivo, por exemplo) podem ter como resultado agressões graves que podem culminar em morte. A mediadora introduz, então, o conceito de "cuidado de si", elaborado com as estudantes, que tem como pressuposto o reconhecimento de si como alguém a quem a dignidade e a vida sejam reconhecidas e valorizadas; reconhecer a si mesma como sujeito integral dotado de uma vida digna de cuidado é um primeiro passo importante no questionamento da violência que tem o corpo da mulher como lócus privilegiado do poder fálico em nossa sociedade.

A profundidade emocional destas etapas é fechada com a apresentação de leis de proteção às mulheres vítimas de violência (Lei Maria da Penha, Lei do minuto seguinte, Lei do feminicídio) com objetivo de demonstrar que o Estado oferece minimamente recursos para que a violência contra a mulher seja enfrentada. Em seguida, foi feita a distribuição de pequenos panfletos que apresentam uma rede mínima de atendimento às mulheres vítimas de violência na cidade de São Paulo com ênfase em serviços próximos ao local de residência das estudantes. Um abraço coletivo amoroso e agradecimentos a cada colega encerraram a tarde de um encontro intenso com promessas de reencontros cotidianos no decurso do curso FIC.

\section{Comentários finais}

No relato desta experiência de realização de uma oficina sobre violência contra a mulher, no bojo do projeto "Empoderamento Feminino através da geração de renda pelas vendas", desenvolvido no âmbito do Projeto Mulheres IFSP, no campus São Paulo-Pirituba, tentei articular a discussão na literatura sobre o tema violência contra a mulher ao desenho de uma metodologia de oficina que tivesse como fundamento a escuta qualificada, o compartilhamento e o acolhimento de experiências. A metodologia tem como objetivo colocar

Revista Extensão \& Cidadania, v. 9, n. 15, p. 154-165 jan./jun. 2021. 
cada mulher participante como o centro da atenção e como sujeito dos discursos sobre violência; longe de reificar uma posição de vítima sem voz, privilegiamos, na condução da oficina, histórias, sofrimentos, amores e resistências nas vozes de mulheres múltiplas e diversas em suas experiências cotidianas.

Atenta à experiência retratada por Gregori (1989), tentei, por meio desta oficina, considerar, a partir de uma escuta sensível, a lógica que opera, ordena e dá sentido à violência contra as mulheres como uma forma de enfrentá-la. Sem sombra de dúvida, é uma aventura repleta de escuta de sofrimentos, mas também de possibilidades desenhadas pelas próprias mulheres. Evitar qualquer projeção de nossa ética política sobre as mulheres é condição primordial para escutar, acolher e construir coletivamente elaborações simbólicas e práticas de saída de situações de violência.

\section{Referências}

AFONSO, Maria L. Oficinas em dinâmica de grupo: um método de intervenção psicossocial. Belo Horizonte: Edições do Campo Social, 2000.

BANDEIRA, Lourdes. Violência de gênero: a construção de um campo teórico e de investigação. Revista Sociedade e Estado, v. 29, n. 2, p. 449-469, 2014.

CARVALHO, Alysson; RODRIGUES, Cristiano; MEDRADO, Kelma. Oficinas em sexualidade humana com adolescentes. Estudos de Psicologia, v. 10, n. 3, p. 377-384, 2005.

FÓRUM DE SEGURANÇA Pública; DECODE. Violência Doméstica durante a Pandemia e COVID 19. São Paulo, 2020. Disponível em: https://forumseguranca.org.br/wpcontent/uploads/2018/05/violencia-domestica-covid-19-v3.pdf. Acesso em: 30 abr. 2021.

GREGORI, Maria Filomena. Cenas e queixas: mulheres e relações violentas. Novos Estudos Cebrap, São Paulo, v. 23, 1989.

IPEA- INSTITUTO DE PESQUISA ECONÔMICA APLICADA (org.). Atlas da Violência 2020. Brasília: IPEA, 2020.

SCOTT, Joan. Gênero: uma categoria útil de análise histórica. Educação \& Realidade, v. 20, n. 2, jul./dez. 1995.

WAISELFISZ, Julio. Mapa da Violência 2015. Homicídio de mulheres no Brasil. Brasília: FLACSO, ONU Mulheres; OPAS/OMS; SPM/PR; 2015.

Revista Extensão \& Cidadania, v. 9, n. 15, p. 154-165 jan./jun. 2021. 